\title{
Metabolic Adaptation in Developing Lung
}

\author{
JOSEPH B. WARSHAW, M.D., ${ }^{(37)}$ MARY L. TERRY, AND MICHAEL B. RANIS \\ Division of Perinatal Medicine, Department of Pediatrics, Yale University School of Medicine, New Haven, \\ Connecticut, USA
}

\section{Summary}

We have carried out studies using rat lung slices showing that the developing lung utilizes both glucose and fatty acids as oxidative substrates. Glucose oxidation to $\mathrm{CO}_{2}$ decreased at birth but showed higher activity after weaning. The activity of the pentose phosphate pathway also decreased postnatally. In contrast to glucose, the oxidation of palmitate and caprate to $\mathrm{CO}_{2}$ showed an increase in the immediate postnatal period. Cytochrome oxidase and carnitine palmitoyltransferase showed a parallel postnatal increase following the increase in fatty acid oxidation. Cytochrome oxidase activity in adult lung was approximately $30 \%$ of peak newborn values. Palmitate incorporation into total lipids was greatest at 18 to 19 days of fetal development, at which time the lung content of nonesterified fatty acids was highest.

\section{Speculation}

The changes in substrate oxidation and utilization observed in developing lung probably reflect changes in the availability of substrates and requirements for precursors to support functional and morphologic differentiation of lung. Changes in cytochrome oxidase activity in the postnatal period may reflect differential lung growth.

The developing lung requires energy for growth and maturation as well as for the synthesis of surface active phospholipids which maintain postnatal alveolar stability. Although there is considerable information concerning glucose and fatty acid metabolism in adult lung, little is known about fatty acid and glucose oxidation in the developing lung. Early work by Geyer $e t$ al. (8) showed that adult rat lung slices oxidized radiolabeled triolein and octanoic acid to ${ }^{14} \mathrm{CO}_{2}$. Subsequent studies by Felts (7) using adult rat lung slices demonstrated oxidation of $\left[1-{ }^{14} \mathrm{C}\right]$ palmitate to ${ }^{14} \mathrm{CO}_{2}$. This work was confirmed by Salisbury-Murphy et al. (18) in rabbit and later by Wang and Meng (24) in the rat. Shaw and Rhoades (19) in the perfused rat lung reported that high concentrations of palmitate $(1.8 \mathrm{mM})$ inhibited glucose oxidation to $\mathrm{CO}_{2}$, suggesting that under some conditions palmitate may be a preferred substrate.

We have previously demonstrated developmental increases in the oxidation of fatty acids by heart, liver, and brain (25-27). The changes occur in the immediate postnatal period when the newborn is exposed to the high fat content of milk, and there is a marked change in the oxygen environment after separation from the uteroplacental circulation.

The aim of the present investigation was to investigate substrate metabolism in the developing rat lung and relate this to pulmonary lipid synthesis.

\section{METHODS}

Timed pregnant rats (30) were stunned by a blow to the head and exsanguinated, and the uteri were removed rapidly. The fetuses were cleared of membranes and decapitated, and the lungs removed to ice-cold Krebs-Ringer Phosphate (KRP), pH 7.4. Newborns were allowed to deliver spontaneously, and at appro- priate ages, the pups were decapitated, and the lungs were excised and placed in the cold buffer as above. Lung slices of 1.0-mm thickness were prepared with a McIlwain tissue chopper (31). Slices were blotted dry and weighed, and 30 to $50 \mathrm{mg}$ placed in 10 ml Ehlernmeyer flasks (32) containing $1 \mathrm{ml}$ of KRP and substrate. Substrates used were $10 \mathrm{mM}$ glucose containing $\left[U_{-}{ }^{14} \mathrm{C}\right]$ glucose (33) to give a specific activity of $0.125 \mathrm{Ci} / \mathrm{mole}$. $\left[1{ }^{14} \mathrm{C}\right]$ glucose and $\left[6-{ }^{14} \mathrm{C}\right]$ glucose at a specific activity of $0.075 \mathrm{Ci} / \mathrm{mole}$ were also used as substrates. Fatty acids (34) combined with unlabeled fatty acids and bound to albumin (20) were added to KRP to give concentrations of $400 \mu \mathrm{M}$ palmitic acid, specific activity, $1 \mathrm{Ci}$ / mole, and $100 \mu \mathrm{M}$ capric acid, specific activity, $0.5 \mathrm{Ci} / \mathrm{mole}$. These concentrations were chosen because they gave optimal rates of oxidation.

The flasks were fitted with rubber caps and polypropylene center wells and incubated in a shaking water bath at $37^{\circ} \mathrm{C}$ for one hr. Under these conditions, production of ${ }^{14} \mathrm{CO}_{2}$ from labeled substrates was linear for at least $2 \mathrm{hr}$. At the end of the incubation, $0.3 \mathrm{ml}$ of hyamine hydroxide was injected through the serum cap into the center well to trap evolved ${ }^{14} \mathrm{CO}_{2}$, the reaction was terminated, and $\mathrm{CO}_{2}$ was released by the injection of $1 \mathrm{ml}$ of $20 \%$ trichloroacetic acid through the cap down the side of the flask into the incubation medium. After $45 \mathrm{~min}$ of further incubation, the contents of the center well were transferred to counting vials containing $10 \mathrm{ml}$ of Econofluor (33), and radioactivity was measured in a liquid scintillation counter (35). Blanks were incubated along with the samples and treated in the same way. Standards were prepared containing $100 \mu$ lof the incubation mix and counted in $10 \mathrm{ml}$ of Aquasol (33). The flasks or medium were not oxygenated because this did not affect the rate of substrate oxidation to $\mathrm{CO}_{2}$.

For measurement of fatty acid incorporation into lipid, slices (50 to $200 \mathrm{mg}$ wet wt) were incubated at the same substrate concentrations in $2 \mathrm{ml}$ of medium. The reaction was terminated by transfer of the flask to ice. The medium then was aspirated, and the tissue was washed with ice-cold $0.9 \%$ saline until the wash was free of radioactivity (about five washes). The slices were then removed with forceps to a Dounce homogenizer and homogenized in $1.6 \mathrm{ml}$ of cold $0.9 \%$ saline. The homogenate was transferred to a stoppered centrifuge tube, $6 \mathrm{ml}$ of chloroform:methanol (1:2) were added, and the tubes were refrigerated for later extraction and analysis. Lipid extraction was then carried out by the method of Bligh and Dyer (2). An aliquot of the chloroform layer was dried, taken up in water $(0.2 \mathrm{ml})$, and counted in Aquasol to give total lipid values.

Lipid classes were separated by the method of Rooney $e t$ al. (17) on small Unisil (36) columns (6-inch Pasteur pipettes containing $0.5 \mathrm{~g}$ Unisil in chloroform). Neutral lipids, glycolipids, and phospholipids were sequentially eluted by washing the columns with $25 \mathrm{ml}$ chloroform, $10 \mathrm{ml}$ acetone, and $10 \mathrm{ml}$ chloroform: methanol (1:9). The collected fractions were evaporated to dryness under nitrogen and taken up in $1 \mathrm{ml}$ of chloroform. An aliquot of each was taken, the chloroform evaporated, water added, and counted. The remainder was stored under nitrogen in the freezer for subsequent analysis.

An aliquot of the phospholipid fraction was chromatographed on $250-\mu \mathrm{m}$ thick silica gel plates (32). The resolving solution was 
chloroform:methanol:7 $\mathrm{M}$ ammonium hydroxide (60:35:3 by volume). Phospholipid was visualized with iodine vapor and identified by comparison with standards run on the same plate. When all traces of iodine had disappeared, the appropriate areas were scraped into counting vials for determination of radioactivity. The neutral lipid fraction was similarly chromatographed using a solvent system consisting of petroleum ether (boiling point, 35$60^{\circ} \mathrm{C}$ ):diethyl ether:glacial acetic acid (85:15:0.8).

Total water content was determined by weight difference after lyophilizing, and the dry tissue was then homogenized in $0.9 \%$ saline and extracted as previously described for lipid analysis. Phospholipid phosphorus was determined on the lipid extract and on the phosphotidylcholine fraction scraped from the thin-layer plate by the method of Dodge and Phillips (6).

Weighed pieces of lung were placed as rapidly as possible in Dole's extraction mix for free fatty acid determination (11).

Carnitine palmitoyltransferase (EC 2.3.1.2) was determined in lung homogenates $(1: 10)$ prepared in $0.25 \mathrm{M}$ sucrose, containing $19 \mathrm{mM}$ Tris-Cl, $\mathrm{pH} 7.5$, and $0.05 \mathrm{mM}$ EDTA by the method of Bremer and Norum (3). Cytochrome oxidase was measured on the

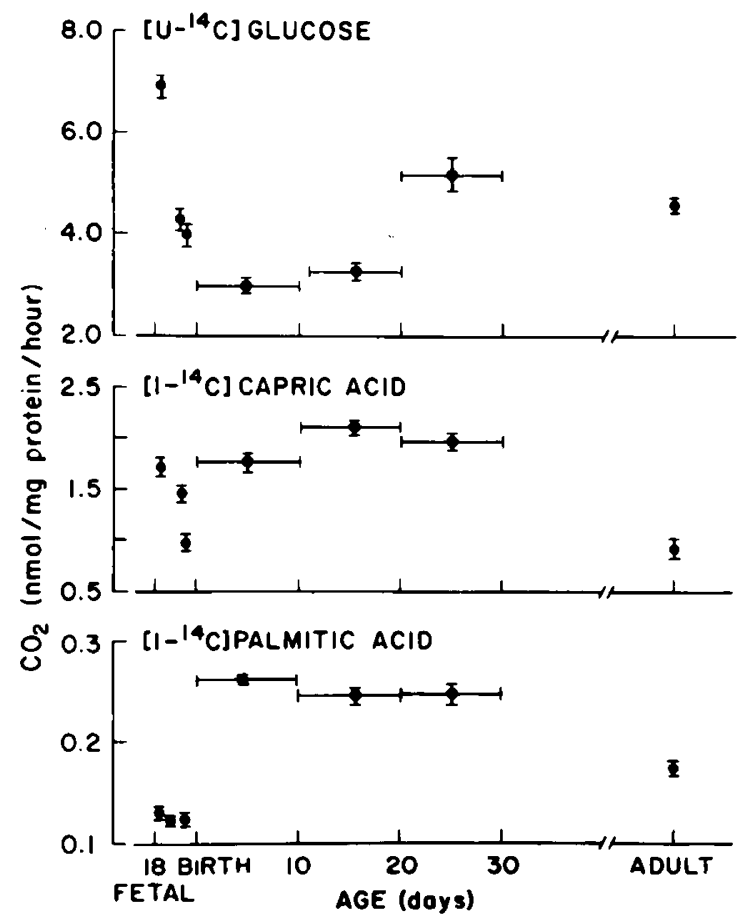

Fig. 1. Fatty acid and glucose oxidation by developing lung. Points, fetal and adult activity represents mean \pm S.E. of at least 4 different experiments. Assays carried out between 1 and 30 days of age are presented in 10-day groups each with at least 10 different experiments \pm S.E. same homogenates polarographically as previously described (25). Protein was measured by the method of Lowry et al. (12).

\section{RESULTS}

Fatty acid oxidation by slices prepared from developing rat lung increased during the postnatal period. Figure 1 compares the oxidation of $\left[U-{ }^{14} \mathrm{C}\right]$ glucose, $\left[1-{ }^{14} \mathrm{C}\right]$ caprate, and $\left[1-{ }^{14} \mathrm{C}\right]$ palmitate by fetal, newborn, and adult lung. Oxidation of glucose to $\mathrm{CO}_{2}$ decriased postnatally during the suckling period when animals were receiving a high fat milk diet. At 20 days of age, glucose oxidation to $\mathrm{CO}_{2}$ increased in association with weaning and a shift in nutrition to a diet higher in carbohydrate. The oxidation of [1${ }^{14} \mathrm{C}$ caprate decreased between days 18 and 22 fetal age and showed an increase in activity in the immediate postnatal period. Oxidation of palmitate to $\mathrm{CO}_{2}$ showed a striking postnatal increase, although rates of oxidation were less than those found with caprate. Addition of $1.0 \mathrm{mM}$ carnitine, $2.6 \mathrm{mM} \mathrm{Ca}{ }^{2+}$, or $1 \mathrm{mM}$ glucose to the assay medium did not increase the rate of palmitate oxidation. Oxidation by lung slices of both caprate and palmitate was less in the adult than during the suckling period.

As shown in Table $1,{ }^{14} \mathrm{CO}_{2}$ production from $\left[1-{ }^{14} \mathrm{C}\right.$ lglucose decreased during late fetal development, increased at birth, and then decreased postnatally. $\left[6-{ }^{14} \mathrm{C}\right]$ Glucose oxidation also decreased between fetal days 18 and 21 but increased postnatally. The ratio of oxidation of $\left[1-{ }^{14} \mathrm{C}\right]$ glucose to $\left[6-{ }^{14} \mathrm{C}\right] \mathrm{glucose}$, an index of pentose phosphate pathway activity, fell from 5.3 at birth to less than 2.1 postnatally.

Lung water and protein content were measured to determine if compositional differences could account for the developmental changes in oxidation. As shown in Table 2, these changes were small. The water content in rat lung decreased from $85.8 \%$ at 22 days fetal age to $81.9 \%$ at one day of age. This value remained constant during the first 30 days. The adult value was $\mathbf{7 8 . 9 \%}$. Protein content per $g$ of dry tissue increased prior to birth and showed a gradual postnatal increase to an adult level of $682 \mathrm{mg} /$ g dry weight.

Because of its central role in mitochondrial fatty acid oxidation, we measured the activity of carnitine palmitoyltransferase in developing lung. As is shown in Figure 2, an increase in activity was seen after birth. Activity was lower after weaning and in the adult. Cytochrome oxidase, which provides an index of mitochondrial number, was also measured in lung homogenates during development. Also shown in Figure 2, this activity increased postnatally and then decreased to adult levels which were less than peak fetal and newborn activities. The ratio of carnitine palmitoyltransferase to cytochrome oxidase was relatively constant during the newborn period, suggesting that increased carnitine palmitoyltransferase activity reflected the increase in lung mitochondrial number observed in the postnatal period. Lung mitochondrial number per mg lung protein and carnitine palmitoyl-

Table 1. Oxidation of $\left[1-{ }^{14} \mathrm{C}\right]$ glucose and $\left[6-{ }^{14} \mathrm{C}\right]$ glucose to ${ }^{14} \mathrm{CO}_{2}$ in developing lung

\begin{tabular}{|c|c|c|c|}
\hline Age (days) & $\begin{array}{l}{ }^{14} \mathrm{CO}_{2} \text { from }\left[1-{ }^{14} \mathrm{C}\right] \text { glucose (nmoles/mg pro- } \\
\text { tein/hr) }\end{array}$ & $\begin{array}{l}{ }^{14} \mathrm{CO}_{2} \text { from }\left[6-{ }^{14} \mathrm{C}\right] \text { glucose (nmoles/mg pro- } \\
\text { tein/hr) }\end{array}$ & 6 \\
\hline
\end{tabular}

Fetal

$\begin{array}{ll}18-19 & 6.71 \pm 0.77^{1} \\ 20-21 & 4.55 \pm 0.37 \\ 22 & 5.84 \pm 0.22\end{array}$

Newborn

$\begin{array}{ll}1-10 & 3.18 \pm 0.14 \\ 10-20 & 2.43 \pm 0.04 \\ 20-30 & 3.89 \pm 0.16\end{array}$

' Mean \pm S.E. for at least 3 experiments at each age. Conditions are as in the text. 
Table 2. Protein and water content of developing lung

\begin{tabular}{lccccccc}
\hline & \multicolumn{3}{c}{ Fetal } & Newborn & Adult \\
\hline Age (days) & $18 \pm 19^{1}$ & $20+21$ & 22 & $1-10$ & $10-20$ & $20-30$ \\
Water (\%) & $86.5 \pm 0.2$ & $85 \pm 0.2$ & $85.8 \pm 0.3$ & $81.9 \pm 0.2$ & $80.7 \pm 0.4$ & $81.0 \pm 0.4$ & $78.9 \pm 0.1$ \\
Protein (mg/g dry wt) & $494 \pm 23$ & $559 \pm 21$ & $567 \pm 33$ & $566 \pm 22$ & $530 \pm 14$ & $556 \pm 40$ & $682 \pm 52$ \\
\hline
\end{tabular}

${ }^{1}$ Mean \pm S.E.

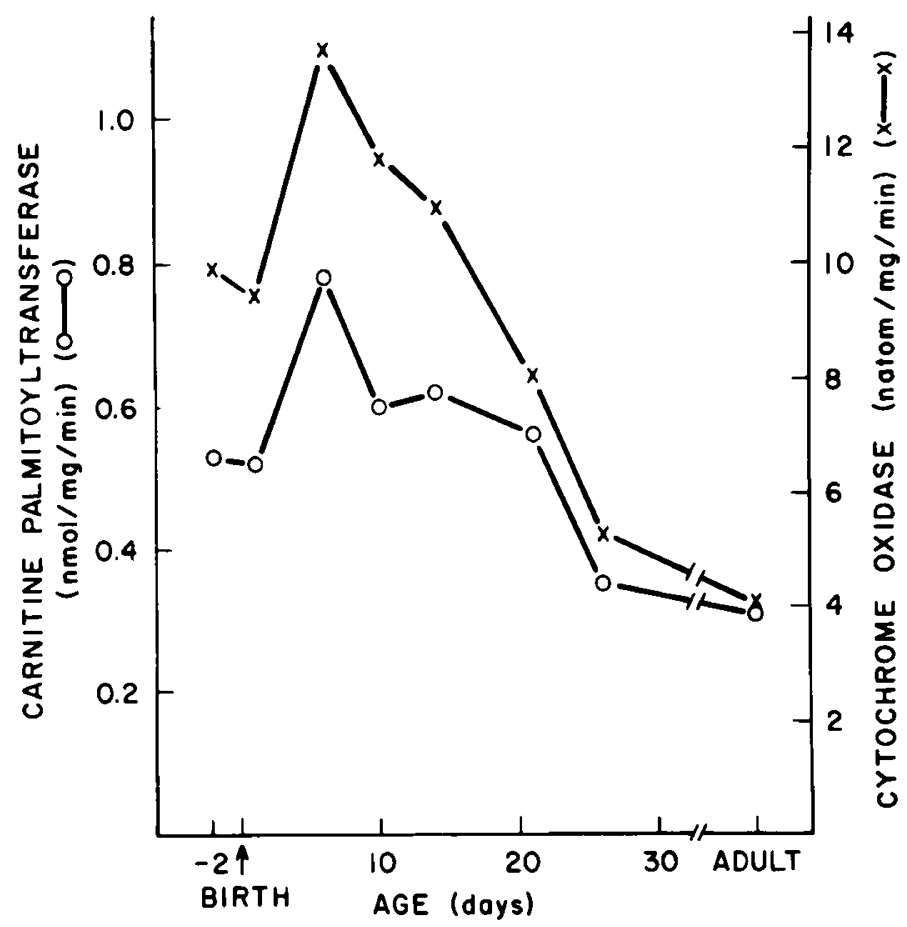

Fig. 2. Developmental profile for carnitine palmitoyltransferase $(O)$ and cytochrome oxidase $(X)$ activities. Assays are as described in the text. Data are expressed per $\mathrm{mg}$ protein.

transferase activity appears to be greatest during the newborn period when energy is required for both growth and surfactant phospholipid synthesis.

Table 3 shows the content of nonesterified, long-chain fatty acids, total phospholipid, and phosphatidylcholine in rat lung at different developmental ages. Free fatty acids were measured to determine the possible influence of fatty acid pool differences on the developmental profiles of fatty acid oxidation. Free fatty acids in lung decreased between days 18 and 22 of fetal development and then showed a postnatal increase which paralleled the postnatal changes in fatty acid oxidation shown in Figure 1. Total phospholipid and phosphatidylcholine content was highest between day 22 of fetal development and 10 days of age. Incorporation of $\left[1-{ }^{14} \mathrm{C}\right]$ palmitate into total lipids was greatest at 18 to 19 days of development (Table 4). From day 18 of fetal development until 10 days of age, over $30 \%$ of the palmitate label was recovered in the phospholipid fraction. After day 10, this decreased to approximately $15 \%$. Phosphatidylcholine accounted for $86 \%$ of recovered radiolabeled phospholipids throughout development. The decrease in palmitate incorporation into phospholipids seen after 10 days of age was also associated with decreased palmitate incorporation into lung triglycerides and cholesterol.

\section{DISCUSSION}

Considerable attention has been focused on developmental aspects of phospholipid synthesis. However, there has been relatively little investigation of oxidative metabolism in developing lung.

Our data as well as that of Villee and Loring (23) and Chida and Adams (4) show that both glucose and fatty acids may be used as oxidative substrates in developing lung. Changes in the rates of glucose and fatty acid oxidation observed may be dependent on substrate availability. With birth, for example, serum levels of free fatty acids increase, and as has been shown previously, there is continued synthesis of fatty acids in newborn lung which provides a continuous flow of precursors for oxidation and lipid synthesis (9).

Cytochrome oxidase activity has been used as an index of mitochondrial number in developing tissues $(5,25)$. The increase in cytochrome oxidase activity that we observed after birth is probably an indication of the greater dependence of the newborn on oxidative metabolism as compared with fetal tissues which develop in a relatively anerobic milieu. During this period of development, there are also large energy requirements for lung growth and for surfactant phospholipid synthesis. Of interest is our observation that cytochrome oxidase activity of adult lung is approximately $30 \%$ of that at 5 days of age. These differences suggest a relative decrease in mitochondrial number and may reflect changing cell populations in lung associated with alveolar growth and differentiation and a decrease in Type II and other cells containing mitochondria as compared with cells with little mitochondrial metabolism such as Type I alveolar cells. On the basis of the proliferative response of Type II cells following lung injury, it has been suggested that Type I cells may be derived from Type II cells during lung repair $(10,21)$. Similar changes of Type II to I cells probably occur during lung development (1). Williams (28) has reported that occasional Type I cells in fetal rat lung retain lamellar bodies. However, in the absence of morphometric confirmation in the present study, we can only speculate that changes in the pattern of cell growth parallel the biochemical profiles that we observed.

The mitochondrial enzyme carnitine palmitoyltransferase has a central role in the transfer of CoA esters of long-chain fatty acids from the cytosol to the mitochondrial sites of $\beta$-oxidation. The parallel increase in activity of carnitine palmitoyltransferase and cytochrome oxidase indicates a constant relationship between the transferase and mitochondrial number during lung development. Massaro et al. (14) found a direct correlation between lung oxygen consumption and the volume of mitochondria in lung Type II cells. In this morphometric-biochemical study, the volume density of mitochondria in Type II cells was considerably greater than in Type I cells, suggesting a greater role for glycolytic metabolism in the latter, whereas Type II cells have a greater potential for oxidative metabolism. That a major part of lung metabolism is glycolytic is suggested by experiments showing high rates of lung lactate production in both tissue slices and in the perfused lung $(15,16,29)$. An active glycolysis is surprising given the highly aerobic milieu of lung, but may reflect diverse metabolic activities.

Oxidation of ${ }^{14} \mathrm{C}$ to ${ }^{14} \mathrm{CO}_{2}$ decreased postnatally during the suckling period but increased in activity after weaning with a shift to a diet higher in carbohydrate content. These changes may be due to nutritional influences (22) but may also relate to decreased activity of the pentose phosphate pathway seen in postnatal lung. Pentose phosphate pathway activity in fetal lung may provide ribose phosphate for nucleotide synthesis and NADPH required for fatty acid synthesis during the fetal period of rapid lung growth (13). Pentose pathway activity in postnatal lung may, in addition, participate in protection of lung from oxidant injury. Large changes in lung glycogen content during development as well as changes in substrate flow to lung associated with birth and suckling may also influence glucose pools and thereby affect activity.

The nonesterified fatty acid content of lung was highest at 18 to 19 days of fetal development. This may reflect transfer of fatty acids across the placenta as well as active endogenous fatty acid 
Table 3. Lipid content of developing lung

\begin{tabular}{lcccc}
\hline Age (days) & Nonesterified fatty acid & Total phospholipid & Phosphatidylcholine & \% phosphatidylcholine \\
\hline Fetal & & & & \\
18 & $66.8 \pm 2.3^{1}$ & $216.7 \pm 7.3$ & $98.4 \pm 3.6$ & 45 \\
20. & $46.0 \pm 2.2$ & $250.8 \pm 12.1$ & $123.5 \pm 6.2$ & 59 \\
22 & $45.5 \pm 0.9$ & $280.7 \pm 4.3$ & $139.6 \pm 2.5$ & 50 \\
Newborn & & & & \\
& & & & \\
$1-10$ & $68.8+1.5$ & $289.2 \pm 9.7$ & $130.2 \pm 2.5$ & 45 \\
$10-20$ & $66.0 \pm 1.7$ & $265.0 \pm 4.2$ & $112.1 \pm 6.6$ & 47 \\
$20-30$ & $68.3 \pm 2.7$ & $236.3 \pm 13.6$ & & \\
Adult & & & $98.5 \pm 5.7$ & 49 \\
\hline
\end{tabular}

'nmoles/mg protein + S.E.

Table 4. $\left[1-{ }^{14} \mathrm{C}\right]$ Palmitate incorporation into total lung lipid and phospholipid

\begin{tabular}{ccc}
\hline Age & $\begin{array}{c}\text { Total lipid' } \\
\text { (nmoles/mg protein } / \mathrm{hr})\end{array}$ & $\begin{array}{c}\text { Phospholipid }^{2} \text { (\% total } \\
\text { lipid) }\end{array}$ \\
\hline
\end{tabular}

Fetal

$\begin{array}{lll}18-19 & 9.82 \pm 0.22 & 32 \\ 20-21 & 6.35 \pm 0.51 & 36 \\ 22 & 4.92 \pm 0.06 & 34\end{array}$

Newborn

$\begin{array}{lll}1-10 & 6.64 \pm 0.28 & 29 \\ 10-20 & 4.11 \pm 0.31 & 14 \\ 20-30 & 4.42 \pm 0.93 & 16 \\ & & \\ \text { Adult } & 4.71+0.49 & 15\end{array}$

'nmoles of $\left[1-{ }^{14} \mathrm{C}\right]$ palmitate incorporated per $\mathrm{mg}$ lung protein per $\mathrm{hr}$ \pm S.E. of at least 3 experiments at each age.

${ }^{2}$ Percentage of palmitate counts recovered as phospholipid after unisil column.

synthesis in fetal lung and liver to meet substrate requirements for lung growth and metabolism at that time.

$\left[1-{ }^{4} \mathrm{C}\right] \mathrm{Palmitate}$ was incorporated readily into lung lipids but was oxidized at a slower rate than caprate. The high rate of [1${ }^{14} \mathrm{C}$ ]caprate oxidation to ${ }^{14} \mathrm{CO}_{2}$ suggests an active $\beta$-oxidation in neonatal and adult lung. The active incorporation of $\left[1-{ }^{14} \mathrm{C}\right] \mathrm{palmi}-$ tate into total lung lipid during late fetal and early newborn development probably relates to rapid lung growth and requirements for pulmonary surfactant.

\section{REFERENCES AND NOTES}

1. Adamson, I. Y. R., and Bowden, D. H.: Deviration of Type I epithelium from Type II cells in the developing rat lung. Lab. Invest., 32: 736 (1975).

2. Bligh, E. G., and Dyer, W. J.: A rapid method of total lipid extraction and purification. Can. J. Biochem. Physiol., 37: 911 (1959).

3. Bremer, J., and Norum, K.: The effects of detergents on palmitoyl coenzyme A: carnitine palmitoyltransferase. J. Biol. Chem., 242: 1749 (1967).

4. Chida, N., and Adams, F. H.: Incorporation of palmitate, glucose and choline into lecithin by fetal and newborn lamb lung. Pediatr. Res., $1: 364$ (1967).

5. DeVos, M. A., Wilmink, C. W., and Hommes, F. A.: Development of some mitochondrial oxidase systems of rat liver. Biol. Neonat., 13: 83 (1968).

6. Dodge, J. T., and Phillips, G. B.: Composition of phospholipids and of phospholipid fatty acids and aldehydes in human red cells. J. Lipid Res., 8: 667 (1967).

7. Felts, J. M.: Carbohydrate and lipid metabolism of lung tissue in vitro. Med. Thorac., 22: 89 (1965).

8. Geyer, R. P., Matthews, L. W., and Stare, F. J.: Metabolism of emulsified trilaurin $\left(-\mathrm{C}^{14} 00-\right)$ and octanoic acid $\left(-\mathrm{C}^{14} 00-\right)$ by rat slices. J. Biol. Chem., 178: 1037 (1950).

9. Gross, I., and Warshaw, J. B.: Enzyme activities related to fatty acid synthesis in developing mammalian lung. Pediatr. Res., 8: 193 (1974).
10. Kapanci, Y., Weibel, E. R., Kaplan, H. P., and Robinson, F. R.: Pathogenesis and reversibility of the pulmonary lesions of oxygen toxicity in monkeys. II Ultrastructural and Morphometric Studies. Lab. Invest., 20: 101 (1969).

11. Kvam, D. C., Schmidt, J. G., Riggilo, D. A., and Gallo, D. G.: Colorimetric microdetermination of plasma free fatty acids. J. Pharm. Sci., 53: 988 (1964).

12. Lowry, O. H., Rosebrough, N. J., Farr, A. L., and Randall, R. J.: Protein measurement with the folin phenol reagent. J. Biol. Chem., 193: 265 (1951).

13. Maniscalco, W., Wilson, C. M., Gross, I., Gobran, L., Rooney, S. A., and Warshaw, J. B.: Development of glycogen and phospholipid metabolism in fetal and newborn rat lung. Biochim. Biophys. Acta, 530. 333 (1978).

14. Massaro, G. D., Gail, D. B., and Massaro, D. J.: Lung oxygen consumption and mitochondria of alveolar epithelial and endothelial cells. J. Appl. Physiol., 38: 588 (1975).

15. O'Neil, J. J., and Tierney, D. F.: Rat lung metabolism: Glucose utilization by isolated perfused lungs and tissue slices. Am. J. Physiol., 226: 867 (1974).

16. Rhoades, R. A.: Net uptake of glucose, glycerol, and fatty acids by the isolated perfused rat lung. Am. J. Physiol., 226: 144 (1974).

17. Rooney, S. A., Canavan, P. M., and Motoyama, E. K.: The identification of phosphatidylglycerol in the rat, rabbit, monkey and human lung. Biochim. Biophys. Acta, 360. 56 (1974).

18. Salisbury-Murphy, S., Rubinstein, D., and Beck, J. C.: Lipid metabolism in lung slices. Am. J. Physiol., 211: 988 (1966).

19. Shaw, M. E., and Rhoades, R. A.: Substrate metabolism in the perfused lung: response to changes in circulating glucose and palmitate levels. Lipids, 12: 930 (1977).

20. Spector, A. A., and Hoak, J. C.: An improved method for the addition of longchain free fatty acid to protein solutions. Anal. Biochem., 32: 297 (1969).

21. Stephens, R. J., Sloan, M. F., Evans, M. J., and Freeman, G.: Early response of lung to low levels of ozone. Am. J. Pathol., 74: 31 (1973).

22. Vernon, R. G., and Walker, D. G.: Adaptive behaviour of some enzymes involved in glucose utilization and formation in rat liver during the weaning period. Biochem. J., 106: 331 (1968).

23. Villee, C. A., and Loring, J. M.: Alternative pathways of carbohydrate metabolism in foetal and adult tissues. Biochem. J., 81: 488 (1961).

24. Wang, M. C., and Meng, H. C.: Lipid synthesis by rat lung in vitro. Lipids, 7: 207 (1972).

25. Warshaw, J. B.: Cellular energy metabolism during fetal development IV. Fatty acid activation, acyl transfer and fatty acid oxidation during development of the chick and rat. Dev. Biol., 28: 537 (1972).

26. Warshaw, J. B., and Terry, M. L.: Cellular energy metabolism during fetal development II. Fatty acid oxidation by the developing heart. J. Cell. Biol., 44: 354 (1970).

27. Warshaw, J. B., and Terry, M. L.: Cellular energy metabolism during fetal development. VI. Fatty acid oxidation by developing brain. Dev. Biol., 52: 161 (1976).

28. Williams, M. C.: Development of the alveolar structure of the fetal rat in late gestation. Fed. Proc., 36: 2653 (1977).

29. Yeager, H., Jr., and Massaro, D.: Glucose metabolism and glycoprotein synthesis by lung slices. J. Appl. Physiol., 32: 477 (1972).

30. Charles River Labs, Cambridge, MA.

31. Brinkman Instruments, Westbury, NY.

32. Kontes Glass Co., Vineland, NJ.

33. New England Nuclear, Boston, MA.

34. Amersham-Searle, Arlington Hts., IL.

35. Beckman Instrument Co., Palo Alto, CA.

36. Clarkson Chemical Co., Williamsport, PA.

37. Requests for reprints should be addressed to: Joseph B. Warshaw, M.P epartment of Pediatrics, Yale University School of Medicine, New Haven, CT 06510 (USA).

38. This research was supported by USPHS Grant HD-08293.

39. Received for publication May 21, 1979.

40. Accepted for publication July 31, 1979. 